Research Article

\title{
Effects of Model Horizontal Grid Resolution on Short- and Medium-Term Daily Temperature Forecasts for Energy Consumption Application in European Cities
}

\author{
G. Giunta, ${ }^{1}$ R. Salerno ${ }^{(D},{ }^{2}$ A. Ceppi ${ }^{1},{ }^{3}$ G. Ercolani, ${ }^{3}$ and M. Mancini ${ }^{3}$ \\ ${ }^{1}$ Eni S.p.A., Development Operations \& Technology, San Donato Milanese, Italy \\ ${ }^{2}$ Epson Meteo Centre-Expert Meteo, Sesto San Giovanni, Italy \\ ${ }^{3}$ Department of Civil and Environmental Engineering, Politecnico di Milano, Milan, Italy
}

Correspondence should be addressed to A. Ceppi; alessandro.ceppi@polimi.it

Received 21 December 2018; Revised 13 March 2019; Accepted 22 April 2019; Published 8 May 2019

Academic Editor: Hisayuki Kubota

Copyright (c) 2019 G. Giunta et al. This is an open access article distributed under the Creative Commons Attribution License, which permits unrestricted use, distribution, and reproduction in any medium, provided the original work is properly cited.

A short-term forecast of energy consumption is affected by different factors related to the demand in residential, commercial, thermoelectric, and industrial sectors. This demand can be strongly constrained by weather variables, especially temperatures, whose forecast may be very useful to predict the balances between supply and demand, minimizing the risk of price volatility. Energy companies use the relationship between meteorological forecast output and energy request to provide an effective scheduling of national gas and power grids and reduce operational costs in critical periods. This work reports a comparison analysis for short- and medium-term daily temperature forecasts during the period 2013-2014 by using the weather model e-kmf ${ }^{\mathrm{TM}}$ (eni-kassandra meteo forecast), currently adopted in gas and power applications where meteorological output has a key role. This weather forecast system uses different models and initial data to develop probabilistic predictions from a perspective of eleven days ahead. In particular, a set of model runs with horizontal grid spacing of 5.5, 8, 13, and $18 \mathrm{~km}$ with the same domain size are undertaken to assess the sensitivity of temperature to horizontal resolutions. A nonlinear Kalman filter has been also applied to postprocess forecasted data in eight European cities (Milano, Roma, Torino, Napoli, Munich, Paris, Brussels, and London). Filtered forecasts over these cities have been compared to local observations taken from SYNOP (surface synoptic observations) and METAR (meteorological Aerodrome Report) stations. Skill scores of performance have been used to generally assess the forecast reliability up to day +11 . In order to understand the sensitivity to the horizontal resolution, investigations have been carried out even during four specific periods of two weeks with stable and unstable weather conditions.

\section{Introduction}

Energy consumption is strictly correlated to seasonal weather and climatic trends, in particular, for surface temperature and precipitation $[1,2]$. By knowing the temperature on a specific geographical area and giving attention to anomalous phenomena, it is possible to improve the planning of storage, sale, and supply of energy reserves [3].

Efficient operation of modern energy distribution systems often requires forecasting of future energy demand $[4,5]$. Energy companies use the link between temperature variability and energy demand for supply, planning to guard against shortages during the most critical times. For this reason, they are the most active users of weather forecasts and they continue to use these products in their weekly scheduling. Hence, the benefit on short- and medium-term forecasts for energy services lies, first of all, in advance warning for better energy distribution and management. The present study, provided by Eni S.p.A to obtain an accurate and high reliability forecast tool for improving the management on energy market for national and European countries, has been made by using the patented e-kmf ${ }^{\mathrm{TM}}$ weather forecast system (eni-Kassandra Meteo Forecast). By providing short- and medium-term temperature forecast over different European areas of interest and using different horizontal grid resolutions to assess their impacts on the 
quality of prediction, an hourly weather forecast application for gas turbine power generation in Italy has been also carried out [6].

A former preliminary analysis over a short period in the year 2013 has shown how the change of the e-kmf ${ }^{\mathrm{TM}}$ model spatial resolution in the forecast from day +1 to $d a y+5$ might reduce the MAE of $2-4^{\circ} \mathrm{C}$ and improve the performance. In this study, several simulations across 2013 to 2014 have been performed with the e- $\mathrm{kmf}^{\mathrm{TM}}$ model by changing its horizontal resolution and quantifying its impact in terms of computational cost and time to run the e- $\mathrm{kmf}^{\mathrm{TM}}$ model with different spatial grids. The benefits in energy market even in many European cities with a different climate compared to the Mediterranean one in Italy have been evaluated.

To assess the impacts of horizontal grid on the forecast results in the selected areas, vertical resolution and physics have been maintained the same for all simulations (as the daily operative $5.5 \mathrm{~km}$ model), with a forecast horizon up to day +11 . Temperature forecasts scaled on selected cities in Italy (Milano, Torino, Roma, and Napoli), Germany (Munich), Belgium (Brussels), France (Paris), and UK (London) have been compared against observations coming from SYNOP (surface synoptic observations) and METAR (meteorological aerodrome report) stations for a dataset of two years (2013-2014) and, then, for particular periods of two weeks with stable and unstable situations. After the description of the data analysis method in Section 2 and the e-kmf ${ }^{\mathrm{TM}}$ forecast system in Section 3, we analyse and discuss the weather benchmark dataset used in this paper. Finally, conclusions of this paper are reported in Section 5.

\section{Observed and Forecasted Temperature Data}

The area of study includes four Italian cities (Milano, Torino, Roma, and Napoli) and four European cities (London, Brussels, Paris, and Munich). Figure 1 shows the domain of the e-kmf ${ }^{\mathrm{TM}}$ weather forecast model for the selected European cities (green dots).

The e- $\mathrm{kmf}^{\mathrm{TM}}$ model forecasts for each urban centre of the eight selected cities at different spatial resolutions are compared with observed data taken from SYNOP and METAR stations in order to calculate the performance of forecasts at different lead times and for different spatial resolutions. The procedure to spatially and temporally average daily temperature forecasts from raw GRIB (Gridded Binary) files at a given lead time for each analysed city is afterwards described:

(i) Hourly temperatures of the four closest grid points $\left(T_{i_{\text {nw }}}, T_{i_{\text {ne }}}, T_{i_{\text {sw }}}\right.$, and $\left.T_{i_{\text {se }}}\right)$ of the meteorological model for each $i$-th analysed city are selected (Figure 2 ), where $T_{i_{\mathrm{nw}}}, T_{i_{\mathrm{ne}}}, T_{i_{\mathrm{sw}}}$, and $T_{i_{\mathrm{se}}}$ are the hourly temperatures of the north-west, north-east, south-west, south-east, respectively, grid point closest to the city.

(ii) These four hourly temperatures of the four grid points closest to the selected city are averaged out with a simple inverse distance weighting (IDW) method (equation 1) to calculate a hourly mean temperature forecast over the city $\left(\bar{T}_{h}\right)$ :
$\bar{T}_{h}=\frac{T_{i_{\mathrm{nw}}} / d_{\mathrm{nw}}^{2}+T_{i_{\mathrm{ne}}} / d_{\mathrm{ne}}^{2}+T_{i_{\mathrm{sw}}} / d_{\mathrm{sw}}^{2}+T_{i_{\mathrm{se}}} / d_{\mathrm{se}}^{2}}{1 / d_{\mathrm{nw}}^{2}+1 / d_{\mathrm{ne}}^{2}+1 / d_{\mathrm{sw}}^{2}+1 / d_{\mathrm{se}}^{2}}$,

where $d_{\mathrm{nw}}^{2}, d_{\mathrm{ne}}^{2}, d_{\mathrm{sw}}^{2}$, and $d_{\mathrm{se}}^{2}$ are the square values of the distance (in $\mathrm{km}$ ) between the north-west, northeast, south-west, south-east, respectively, grid points closest to the city and the city itself.

(iii) The final step computes the daily temperature forecast $\left(\bar{T}_{\text {daily forecast }}\right)$ of the analysed city averaging out the hourly mean temperatures $\left(\bar{T}_{h}\right)$ as shown in the following equation:

forecast of the daily mean temperature

$$
\left(\bar{T}_{\text {daily forecast }}\right)=\frac{1}{n} \sum_{h=1}^{n} \bar{T}_{h},
$$

where $n$ is equal to 24 for the e-kmf ${ }^{\text {тм }}$ model since the model forecast output $\left(T_{h}\right)$ is every 1 hour.

This aforementioned procedure is repeated for all the 8 cities at all lead times (eleven) of the model forecast (day +0 , $d a y+1, d a y+2$, etc.).

\section{3. e-kmf ${ }^{\mathrm{TM}}$ Meteorological Model}

In this study a multimodel approach based on regional and limited area models has been used $[6,7]$. This local ensemble prediction system has been developed in the framework of the e-kmf ${ }^{\mathrm{TM}}$ weather forecast system where the forecast is produced by multiple modeling sources with varying physics and perturbed initial conditions. Ensemble forecasting provides a useful way of addressing variability in the initial conditions, uncertainties in model physics, and the inherent uncertainty in atmospheric forecast [3]. This system represents an effective attempt to simulate the atmospheric evolution and may provide insights into the range of uncertainties which can be found in both the initial conditions and models. Multimodel approaches, which use a single analysis, attempt to overcome modeling system deficiencies, while multiple analyses with a single modeling system may diagnose sensitivity to the initial conditions. The combination of these two approaches can maximize the benefits of each one by compensating for deficiencies in both the initial conditions and the modeling systems. The e- $\mathrm{kmf}^{\mathrm{TM}}$ consists of multicomponent ensembles: the global ensemble provides lateral boundary conditions to a regional ensemble which provides the boundary conditions to a limited area. In this setup, the regional ensemble provides the downscaling of the global ensemble; the local ensemble, in turn, provides the dynamical downscaling of the regional ensemble. Each higher resolution model provides the opportunity for smallscale features to grow in the ensemble. The local ensemble used in this study is applied on a domain covering the area in Figure 1, using 14 members (the same number of the regional ensemble), a spatial grid resolution varying from $5.5 \mathrm{~km}$ to $18 \mathrm{~km}$ with 42 vertical levels in all simulations, and the same number of levels of the global and the regional models. Dynamical cores are based on the WRF-ARW 

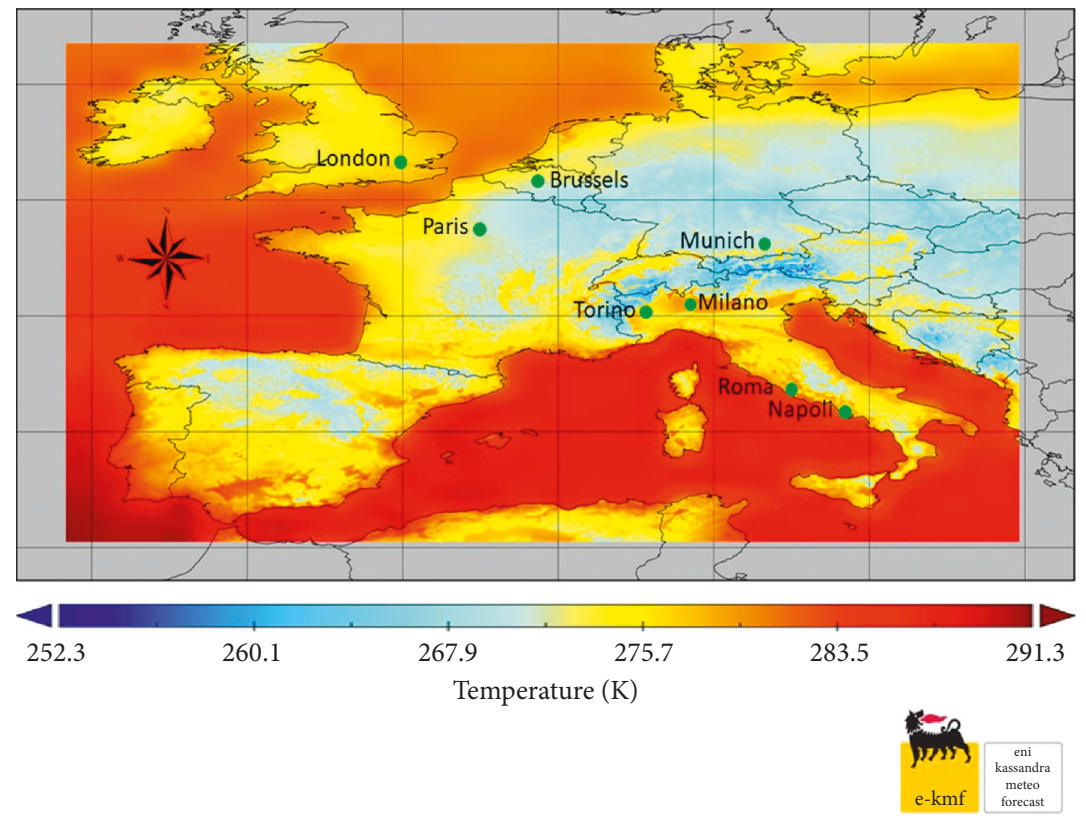

FIGURE 1: e-kmf ${ }^{\mathrm{TM}}$ European domain with the eight cities, where the analysis for short- and medium-term temperature forecasts has been carried out.

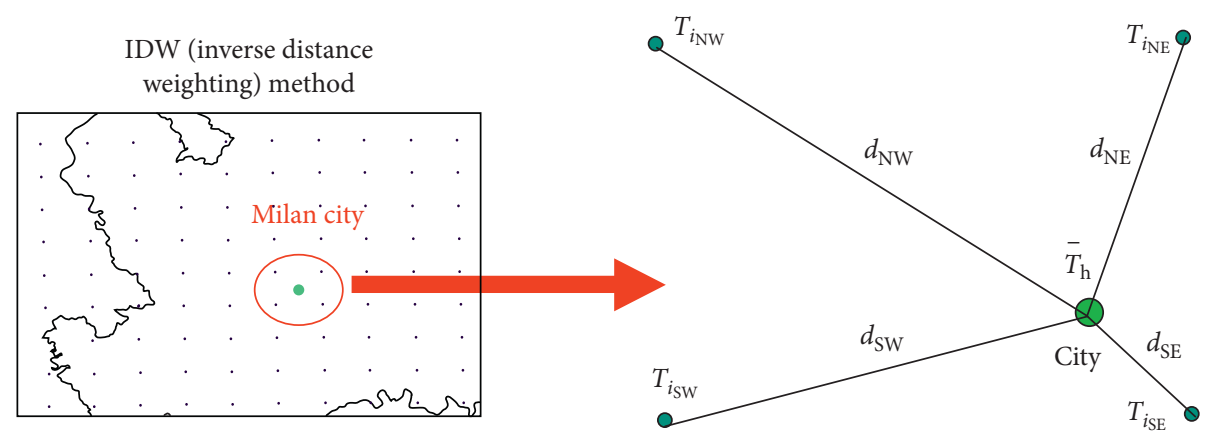

Figure 2: Procedure to calculate the hourly spatial mean temperature forecast $\left(\bar{T}_{h}\right)$.

(Weather Research and Forecasting-Advanced Research), the WRF NMM (nonhydrostatic mesoscale model), and the latest version of Eta model [8]. For each simulation, the multimodel approach uses different physical and dynamic schemes for microphysics $[9,10]$, planetary boundary layer and surface layer [11-16], cumulus parameterization $[17,18]$, radiation [19-21], and land surface physics [22-25].

Each run is then postprocessed through a Kalman filter to obtain local temperature predictions; the operative forecast output is the median temperature computed on these local filtered runs [6]. This e-kmf ${ }^{\mathrm{TM}}$ forecast system is suitable for several applications where forecast of meteorological variables is relevant (e.g., renewable energy, risk analysis, and planning), and it can be applied to any area worldwide.

3.1. Importance of the Horizontal Grid Resolution. The horizontal resolution of a NWP (numerical weather prediction) model is related to the spacing between grid points for grid point models or the number of waves that can be resolved for spectral models. Since the smallest features that can be accurately represented by a model are several times larger than the grid resolution, phenomena with dimensions on the same scale as the grid spacing are unlikely to be depicted or predicted within a model. Whether a model is considered at high or low resolution depends upon the size of the domain and the scale of weather phenomena that the model is trying to predict. A resolution on the order of 10 to $20 \mathrm{~km}$ may be considered high for a global model, while for a storm-scale model, a resolution of $500 \mathrm{~m}$ may be necessary in order to resolve the internal processes. Horizontal resolution has a direct impact on several characteristics such as vertical motions, downward fluxes, precipitation location and strengths, down-slope and valley winds, and mountain waves, among others.

Quite large grid meshes cannot resolve some characteristics of the circulations and, particularly, in complex 
areas, the vertical wind velocities, which do not affect only dynamics, but the thermal and moisture distribution, which has an influence on the wind characteristics and the occurrence and strength of precipitation. High-resolution mesoscale simulations can get better results to describe the circulation patterns, the surface parameters, and the precipitation amounts. Several years ago, in the framework of an integrated modeling approach at regional and local scales, simulations were performed in the Alpine area [26] and results about precipitations fairly well agreed with observations when horizontal resolutions fell below $10 \mathrm{~km}$. Hence, higher resolutions were crucial to improve the location and the values of the precipitations. The simultaneous use of mesoscale models gave a further improvement in the description of weather dynamics and thermodynamics [27]. Many of the deficiencies found in the current global- and synoptic-scale models can therefore be mitigated in mesoscale and local models. The use of vertical coordinates and the vertical resolution also strongly impact the nature of terrain effects.

Many other studies showed the importance of higher resolution in improving the forecast skill [28], in different research fields as convective precipitation [29], fire danger [30], weather prediction, or climate simulations [31, 32]. Furthermore, horizontal resolution has a direct impact on the convection schemes, and convection-permitting models may be required when it is below $3 \mathrm{~km}$. Then, an increased resolution will generally yield more accurate simulations due to the reduction in the dispersion of subgrid-scale phenomena and increasing coverage of wavenumber space, particularly in regions that are topographically complex and exhibit heterogeneous land use. However, increased resolutions are not necessarily associated with an increased model skill or a reduction in model biases [33], and it also comes at substantial computational cost [34].

Finally, even simulations with an identical model running at different resolutions may lead to different behaviours due to nonlinearities in the parameterizations; any change in model behaviour and performance might be parameter specific. For example, some studies have shown that increasing horizontal resolution leads to an increase of quantitative precipitation forecast (QPF) especially over complex topography, which can be dependent to convection, and the impact of model domain size and horizontal resolution on QPF may be quite large comparing with the perturbed physics and initial condition uncertainty [29]. The model skill at small scales is found to be better for stable orographic precipitation than in the presence of embedded convective cells because the latter induces a stochastic component in the precipitation field. The impact of the cloud microphysics scheme increases with increasing model resolution, and in the complex topography areas, the impact of enhancing the model resolution turns out to be small and not necessarily beneficial [35]. On the other side, a nearsurface parameter like temperature might show a different behaviour depending on the model's ability in forecasting the structures in the lower-atmospheric boundary layer, the PBL schemes used in the model, and the flow-dependent features in complex terrain [36], as it is also described in [37], where the overall accuracy of temperature forecasts for the highest resolution grid domain did not fully capture the nocturnal and persistent cold pools within mountain valleys and lowlands.

In this paper, the objective is to evaluate the model performance at different spatial grid resolutions (Figure 3) for the $2 \mathrm{~m}$ air temperature over selected European cities which belong to different climatic conditions.

\section{Results and Discussion}

4.1. Benchmark Analysis. Mean daily temperature forecasts for each of the eight European cities of the e- $\mathrm{kmf}^{\mathrm{TM}}$ model at different spatial resolutions are compared with observed data to calculate the performance evaluation at different lead times. Observed temperature data are available for the years 2013 and 2014, when particular weather periods are also selected to be analysed over the selected cities.

This fortnight is referred to stable and unstable time, where stable means that the meteorological pattern may be generally referred to a presence of a high pressure at synoptic scale with limited temperature changes between the following days, while unstable is referred to a relatively occurrence of low pressure or changeable weather due to the passage of fronts and instabilities with significant variations in temperatures among consecutive days.

Some statistical indexes, commonly known in literature, are used to set up the analysis. Among skill scores, the mean absolute error (MAE) is the one which efficiently represents the magnitude of forecast error in a given verification data set, and it is also daily used by Eni operators for energy and gas planning models. Only the ensemble mean will be used in this paper since this analysis is related to the operational application of the energy consumption model, which can use a single value of temperature. However, the mean of the ensemble scenarios is generally the most accurate forecast [38], and it is more performing than a high-resolution deterministic model prediction.

4.2. Role of Grid Spatial Resolution. To only evaluate impacts of the horizontal grid on the results in the selected areas, vertical resolution (48 levels) and physics have been maintained the same for all simulations. Forecasts scaled on designated cities in Italy, Germany, Belgium, France, and UK are compared at all lead times (11 days in advance) against observations coming from the SYNOP and METAR stations. Statistics describing performances obtained in the various simulations are shown in Tables 1-4.

In terms of MAE, higher resolutions appear more important for cities in Italy (Table 1) than for cities in Europe (Table 2). This is reasonable due to the presence of a complex topography all around Italian cities (mainly Milano and Torino which are in the Po Valley close to mountains and less for Napoli and Roma, where the maritime climate mitigates the daily variations of temperatures), while for European cities of London, Paris, and Brussels, there are no relevant orographic characteristics around; a partial 


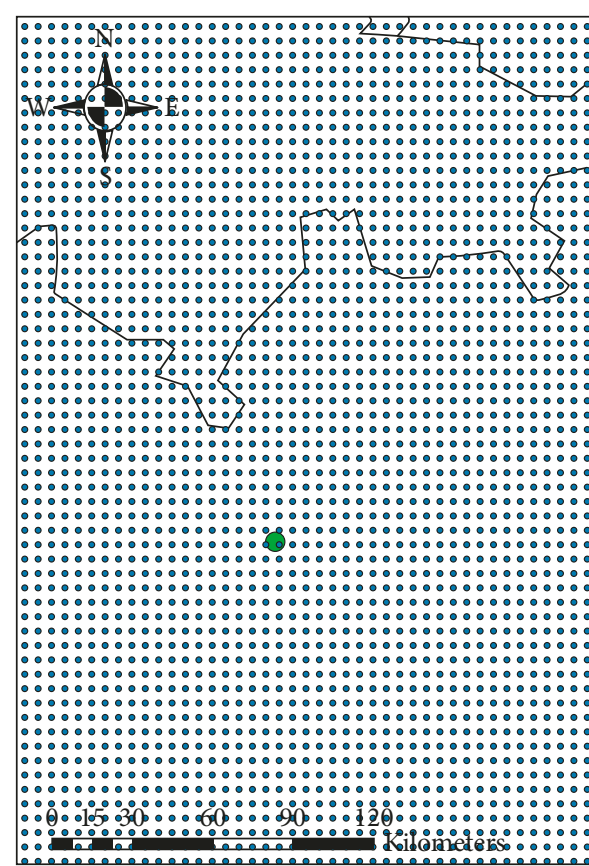

(a)

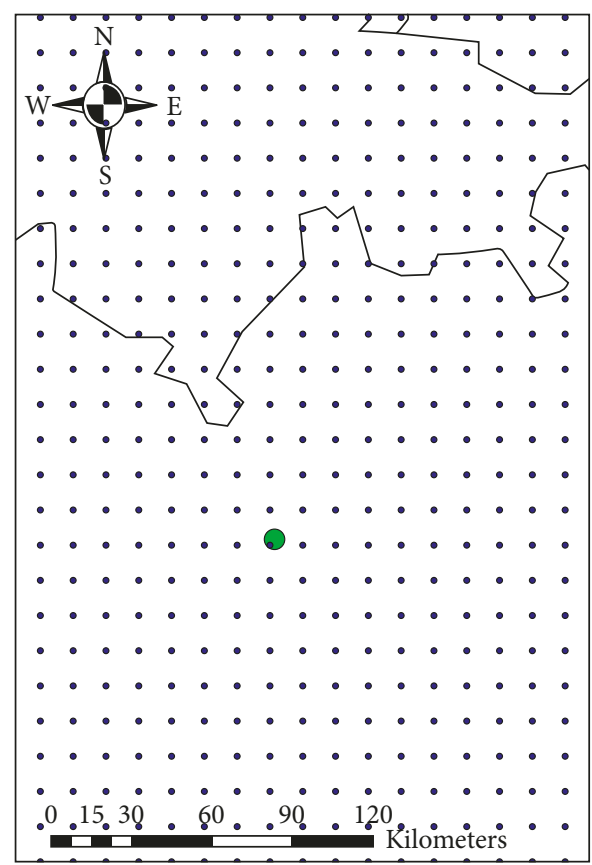

(c)

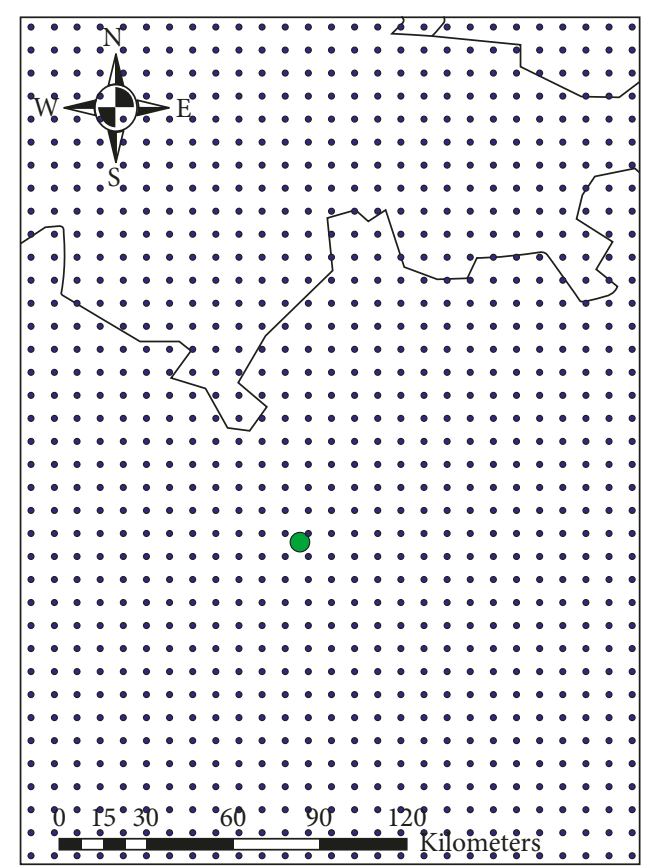

(b)

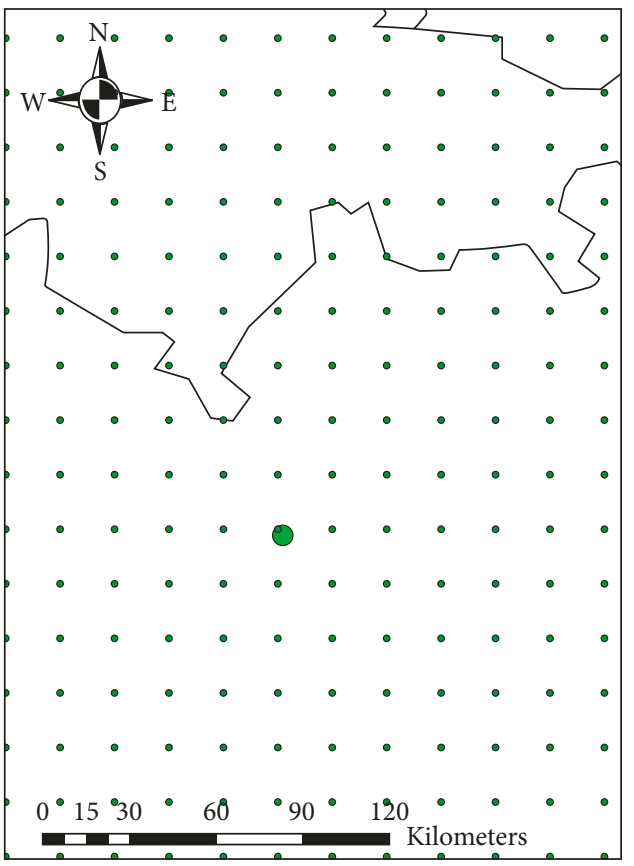

(d)

FIgURe 3: Example of the four grid domains: $5.5 \mathrm{~km}(\mathrm{a}), 8 \mathrm{~km}(\mathrm{~b}), 13 \mathrm{~km}(\mathrm{c})$, and $18 \mathrm{~km}$ (d) of the e-kmf ${ }^{\mathrm{TM}}$ model; the green dot shows the city centre of Milano in the north of Italy.

exception is Munich, in Germany, due to the presence of Alps, southerly to this place.

It appears that the transition from 18 to $5.5 \mathrm{~km}$ grid spacing allows a better definition of the main mesoscale features; in fact, differences in the horizontal grid resolution mean differences in mean model orography. In addition, local fluxes may also depend on the subgrid representation of topography. However, the representation of the mean orography appears to play an important role for the prediction of near-surface temperatures. This is not surprising, since the low-level atmospheric spectra closely follow the mean orography spectra [39]. The degradation in forecast skill resulting from using a smoother mean orography can only partially be alleviated by using more variability in the subgrid orography, and the parameterized drag does not affect the flow in the same way as the resolved drag. $2 \mathrm{~m}$ temperatures of the cities near relevant mountains (Milano, Torino, but also Munich) are, then, influenced by 
TABle 1: MAE of the e- $\mathrm{kmf}^{\mathrm{TM}}$ temperature forecasts at different spatial resolutions and lead times over the Italian cities; values in italics depict a forecast below the $2^{\circ} \mathrm{C}$ error threshold.

\begin{tabular}{lcccccccccccc}
\hline MAE $\left({ }^{\circ} \mathrm{C}\right)$ & $\mathrm{d}+0$ & $\mathrm{~d}+1$ & $\mathrm{~d}+2$ & $\mathrm{~d}+3$ & $\mathrm{~d}+4$ & $\mathrm{~d}+5$ & $\mathrm{~d}+6$ & $\mathrm{~d}+7$ & $\mathrm{~d}+8$ & $\mathrm{~d}+9$ & $\mathrm{~d}+10$ & $\mathrm{~d}+11$ \\
\hline Milano $(5.5 \mathrm{~km})$ & 0.45 & 0.56 & 0.59 & 0.75 & 0.79 & 1.29 & 1.76 & 2.03 & 2.21 & 2.16 & 2.43 \\
Milano $(8 \mathrm{~km})$ & 0.46 & 0.58 & 0.58 & 0.76 & 0.83 & 1.30 & 1.79 & 2.06 & 2.25 & 2.24 & 2.47 \\
Milano $(13 \mathrm{~km})$ & 0.63 & 0.76 & 0.77 & 1.01 & 1.07 & 1.66 & 2.27 & 2.58 & 2.80 & 2.77 & 3.04 & 3.38 \\
Milano $(18 \mathrm{~km})$ & 1.12 & 1.25 & 1.26 & 1.55 & 1.63 & 2.43 & 3.21 & 3.46 & 3.69 & 3.57 & 3.88 & 4.24 \\
\hline Torino $(5.5 \mathrm{~km})$ & 0.59 & 0.74 & 0.85 & 0.80 & 0.83 & 1.19 & 1.78 & 2.28 & 2.28 & 2.42 & 2.39 & 2.61 \\
Torino $(8 \mathrm{~km})$ & 0.40 & 0.62 & 0.69 & 0.87 & 0.89 & 1.27 & 1.92 & 2.48 & 2.65 & 2.84 & 2.80 \\
Torino $(13 \mathrm{~km})$ & 0.55 & 0.84 & 0.94 & 1.16 & 1.19 & 1.65 & 2.46 & 3.14 & 3.31 & 3.55 & 3.51 & 3.78 \\
Torino $(18 \mathrm{~km})$ & 0.96 & 1.37 & 1.52 & 1.77 & 1.79 & 2.37 & 3.41 & 4.17 & 4.29 & 4.48 & 4.44 & 4.66 \\
\hline Roma $(5.5 \mathrm{~km})$ & 0.33 & 0.45 & 0.55 & 0.54 & 0.59 & 1.15 & 1.55 & 1.93 & 1.98 & 1.90 & 2.24 & 2.37 \\
Roma $(8 \mathrm{~km})$ & 0.34 & 0.46 & 0.54 & 0.55 & 0.61 & 1.16 & 1.57 & 1.96 & 2.00 & 1.98 & 2.27 \\
Roma $(13 \mathrm{~km})$ & 0.47 & 0.63 & 0.73 & 0.76 & 0.81 & 1.55 & 2.05 & 2.52 & 2.55 & 2.49 & 2.87 & 3.03 \\
Roma $(18 \mathrm{~km})$ & 0.78 & 1.02 & 1.19 & 1.15 & 1.19 & 2.23 & 2.79 & 3.30 & 3.26 & 3.11 & 3.55 & 3.74 \\
\hline Napoli $(5.5 \mathrm{~km})$ & 0.22 & 0.39 & 0.47 & 0.47 & 0.59 & 0.98 & 1.41 & 1.68 & 1.87 & 1.93 & 2.11 & 2.21 \\
Napoli $(8 \mathrm{~km})$ & 0.24 & 0.40 & 0.47 & 0.49 & 0.63 & 1.01 & 1.43 & 1.73 & 1.96 & 2.07 & 2.18 & 2.27 \\
Napoli $(13 \mathrm{~km})$ & 0.33 & 0.56 & 0.67 & 0.68 & 0.86 & 1.39 & 1.96 & 2.31 & 2.58 & 2.69 & 2.87 & 2.92 \\
Napoli $(18 \mathrm{~km})$ & 0.51 & 0.85 & 1.01 & 0.97 & 1.19 & 1.90 & 2.57 & 2.88 & 3.11 & 3.16 & 3.36 & 3.44 \\
\hline
\end{tabular}

TABLE 2: MAE of the e-kmf ${ }^{\mathrm{TM}}$ temperature forecasts at different spatial resolutions and lead times over the European cities; values in italics depict a forecast below the $2^{\circ} \mathrm{C}$ error threshold.

\begin{tabular}{|c|c|c|c|c|c|c|c|c|c|c|c|c|}
\hline $\operatorname{MAE}\left({ }^{\circ} \mathrm{C}\right)$ & $\mathrm{d}+0$ & $d+1$ & $d+2$ & $d+3$ & $d+4$ & $d+5$ & $d+6$ & $d+7$ & $d+8$ & $\mathrm{~d}+9$ & $\mathrm{~d}+10$ & $d+11$ \\
\hline Brussels $(5.5 \mathrm{~km})$ & 0.83 & 0.87 & 0.91 & 1.07 & 1.25 & 1.52 & 1.48 & 1.34 & 1.33 & 1.51 & 1.76 & 1.88 \\
\hline Brussels $(8 \mathrm{~km})$ & 0.88 & 0.94 & 0.94 & 1.12 & 1.29 & 1.58 & 1.54 & 1.38 & 1.38 & 1.58 & 1.84 & 1.95 \\
\hline Brussels $(13 \mathrm{~km})$ & 0.94 & 0.98 & 0.96 & 1.17 & 1.36 & 1.67 & 1.62 & 1.46 & 1.48 & 1.69 & 1.96 & 2.09 \\
\hline Brussels $(18 \mathrm{~km})$ & 0.97 & 1.01 & 1.01 & 1.21 & 1.40 & 1.73 & 1.66 & 1.50 & 1.49 & 1.71 & 1.96 & 2.09 \\
\hline London $(5.5 \mathrm{~km})$ & 0.51 & 0.57 & 0.66 & 0.92 & 1.09 & 1.32 & 1.43 & 1.04 & 1.14 & 1.38 & 1.56 & 1.64 \\
\hline London $(8 \mathrm{~km})$ & 0.57 & 0.62 & 0.69 & 0.97 & 1.15 & 1.38 & 1.49 & 1.08 & 1.19 & 1.44 & 1.62 & 1.71 \\
\hline London $(13 \mathrm{~km})$ & 0.61 & 0.64 & 0.70 & 0.99 & 1.18 & 1.43 & 1.55 & 1.13 & 1.25 & 1.52 & 1.69 & 1.78 \\
\hline London $(18 \mathrm{~km})$ & 0.62 & 0.65 & 0.71 & 1.01 & 1.21 & 1.48 & 1.59 & 1.15 & 1.28 & 1.54 & 1.71 & 1.81 \\
\hline Paris $(5.5 \mathrm{~km})$ & 0.77 & 0.86 & 0.79 & 1.08 & 1.27 & 1.56 & 1.61 & 1.26 & 1.48 & 1.63 & 1.83 & 2.00 \\
\hline Paris $(8 \mathrm{~km})$ & 0.86 & 0.95 & 0.84 & 1.12 & 1.33 & 1.63 & 1.67 & 1.30 & 1.55 & 1.71 & 1.92 & 2.09 \\
\hline Paris $(13 \mathrm{~km})$ & 0.93 & 0.99 & 0.86 & 1.17 & 1.38 & 1.72 & 1.74 & 1.37 & 1.65 & 1.82 & 2.02 & 2.20 \\
\hline Paris $(18 \mathrm{~km})$ & 0.95 & 1.01 & 0.88 & 1.20 & 1.43 & 1.79 & 1.79 & 1.40 & 1.67 & 1.85 & 2.04 & 2.23 \\
\hline Munich $(5.5 \mathrm{~km})$ & 0.79 & 1.06 & 1.16 & 1.17 & 1.17 & 1.48 & 1.35 & 1.56 & 1.67 & 1.89 & 2.17 & 2.38 \\
\hline Munich $(8 \mathrm{~km})$ & 0.88 & 1.16 & 1.24 & 1.22 & 1.23 & 1.55 & 1.39 & 1.63 & 1.73 & 1.98 & 2.25 & 2.49 \\
\hline Munich $(13 \mathrm{~km})$ & 0.95 & 1.22 & 1.28 & 1.30 & 1.30 & 1.66 & 1.50 & 1.74 & 1.87 & 2.14 & 2.41 & 2.66 \\
\hline Munich $(18 \mathrm{~km})$ & 1.00 & 1.30 & 1.36 & 1.36 & 1.37 & 1.75 & 1.55 & 1.80 & 1.91 & 2.19 & 2.47 & 2.72 \\
\hline
\end{tabular}

the nearby topography, especially, when the interaction between synoptic and mesoscale fluxes with the mountains gives an important contribution to the variability of the near-surface variables.

Forecasts of near-surface variables in flat terrain depend on the predictability of the lower-atmospheric boundary layer. In complex terrain, forecasts not only suffer from the model's inability to reproduce accurate atmospheric conditions in the lower atmosphere but also struggle with representative issues due to mismatches between the model and the actual terrain. In addition, surface forecasts at finer resolutions do not always outperform those at coarser resolutions (see, for instance, the MAE at 5.5 and $8 \mathrm{~km}$, for Torino).

An improvement in the MAE of predicted daily mean temperatures has been obtained with errors generally below $2^{\circ} \mathrm{C}$ (italicized numbers in Tables 1 and 2) in the overall forecasted period. This MAE threshold may be reasonably considered a focal target for the temperature prediction by a meteorological model. In contrast, there are only small improvements in verification statistics as grid spacing decreased from 8 to $5.5 \mathrm{~km}$. Reducing grid spacing provides more detail and structure (e.g., defining steeper orographic slopes), but it has only a limited impact on traditional objective verification scores in the points analysed here. However, in this application, the verification is also necessarily dependent on the needs of the end user; the e- $\mathrm{kmf}^{\mathrm{TM}}$ model, with $18 \mathrm{~km}$ grid resolution, might be suitable for the prediction of near-surface temperatures by the energy consumption application over cities mainly dominated by Atlantic patterns over a week ahead from the initialization date. The same model resolution depicts an analogous performance only until the fourth day over areas where terrain and surface contrasts may have a significant interaction with mesoscale features. At the end, the $8 \mathrm{~km}$ horizontal resolution may result as the best compromise in 
TABLE 3: RMSE of the e-kmf ${ }^{\mathrm{TM}}$ temperature forecasts at different spatial resolutions and lead times over the Italian cities; values in italics depict a good forecast below the $2^{\circ} \mathrm{C}$ error threshold.

\begin{tabular}{|c|c|c|c|c|c|c|c|c|c|c|c|c|}
\hline RMSE $\left({ }^{\circ} \mathrm{C}\right)$ & $\mathrm{d}+0$ & $\mathrm{~d}+1$ & $d+2$ & $\mathrm{~d}+3$ & $\mathrm{~d}+4$ & $d+5$ & $d+6$ & $d+7$ & $d+8$ & $\mathrm{~d}+9$ & $\mathrm{~d}+10$ & $\mathrm{~d}+11$ \\
\hline Milano $(5.5 \mathrm{~km})$ & 0.58 & 0.75 & 0.81 & 0.96 & 0.96 & 1.58 & 2.19 & 2.45 & 2.73 & 2.77 & 2.89 & 3.16 \\
\hline Milano $(8 \mathrm{~km})$ & 0.60 & 0.77 & 0.79 & 0.97 & 0.99 & 1.61 & 2.23 & 2.50 & 2.77 & 2.86 & 2.94 & 3.21 \\
\hline Milano $(13 \mathrm{~km})$ & 0.82 & 0.98 & 1.03 & 1.28 & 1.28 & 2.05 & 2.83 & 3.12 & 3.46 & 3.53 & 3.63 & 3.93 \\
\hline Milano $(18 \mathrm{~km})$ & 1.46 & 1.59 & 1.69 & 1.98 & 1.95 & 3.00 & 4.00 & 4.19 & 4.55 & 4.53 & 4.61 & 4.90 \\
\hline Torino $(5.5 \mathrm{~km})$ & 0.83 & 0.99 & 1.19 & 1.11 & 1.14 & 1.49 & 2.26 & 2.84 & 2.86 & 2.96 & 2.87 & 3.15 \\
\hline Torino $(8 \mathrm{~km})$ & 0.54 & 0.86 & 0.96 & 1.14 & 1.12 & 1.52 & 2.35 & 2.98 & 3.14 & 3.32 & 3.24 & 3.52 \\
\hline Torino $(13 \mathrm{~km})$ & 0.75 & 1.16 & 1.30 & 1.50 & 1.49 & 1.98 & 3.01 & 3.76 & 3.94 & 4.14 & 4.05 & 4.35 \\
\hline Torino $(18 \mathrm{~km})$ & 1.31 & 1.91 & 2.11 & 2.30 & 2.26 & 2.86 & 4.18 & 5.00 & 5.11 & 5.22 & 5.10 & 5.35 \\
\hline Roma $(5.5 \mathrm{~km})$ & 0.46 & 0.56 & 0.67 & 0.71 & 0.79 & 1.42 & 1.90 & 2.36 & 2.49 & 2.62 & 2.79 & 2.79 \\
\hline Roma $(8 \mathrm{~km})$ & 0.48 & 0.58 & 0.66 & 0.72 & 0.81 & 1.44 & 1.93 & 2.40 & 2.53 & 2.71 & 2.83 & 2.83 \\
\hline Roma (13 km) & 0.63 & 0.79 & 0.89 & 0.97 & 1.05 & 1.91 & 2.52 & 3.07 & 3.22 & 3.43 & 3.57 & 3.56 \\
\hline Roma $(18 \mathrm{~km})$ & 1.03 & 1.28 & 1.45 & 1.47 & 1.55 & 2.73 & 3.45 & 4.04 & 4.12 & 4.28 & 4.41 & 4.42 \\
\hline Napoli $(5.5 \mathrm{~km})$ & 0.32 & 0.51 & 0.57 & 0.60 & 0.73 & 1.27 & 1.80 & 2.11 & 2.39 & 2.57 & 2.78 & 2.66 \\
\hline Napoli $(8 \mathrm{~km})$ & 0.33 & 0.52 & 0.58 & 0.61 & 0.77 & 1.31 & 1.82 & 2.19 & 2.51 & 2.74 & 2.87 & 2.74 \\
\hline Napoli $(13 \mathrm{~km})$ & 0.42 & 0.71 & 0.82 & 0.86 & 1.04 & 1.80 & 2.50 & 2.92 & 3.32 & 3.57 & 3.76 & 3.53 \\
\hline Napoli $(18 \mathrm{~km})$ & 0.64 & 1.07 & 1.23 & 1.22 & 1.44 & 2.47 & 3.27 & 3.64 & 3.99 & 4.21 & 4.42 & 4.18 \\
\hline
\end{tabular}

TABLE 4: RMSE of the e-kmf ${ }^{\mathrm{TM}}$ temperature forecasts at different spatial resolutions and lead times over the European cities; values in italics depict a good forecast below the $2^{\circ} \mathrm{C}$ error threshold.

\begin{tabular}{|c|c|c|c|c|c|c|c|c|c|c|c|c|}
\hline RMSE $\left({ }^{\circ} \mathrm{C}\right)$ & $\mathrm{d}+0$ & $\mathrm{~d}+1$ & $d+2$ & $d+3$ & $\mathrm{~d}+4$ & $\mathrm{~d}+5$ & $\mathrm{~d}+6$ & $\mathrm{~d}+7$ & $\mathrm{~d}+8$ & $\mathrm{~d}+9$ & $\mathrm{~d}+10$ & $\mathrm{~d}+11$ \\
\hline Brussels $(5.5 \mathrm{~km})$ & 1.10 & 1.12 & 1.18 & 1.38 & 1.55 & 1.90 & 1.81 & 1.61 & 1.64 & 1.89 & 2.19 & 2.34 \\
\hline Brussels $(8 \mathrm{~km})$ & 1.15 & 1.19 & 1.22 & 1.42 & 1.60 & 1.98 & 1.88 & 1.66 & 1.70 & 1.98 & 2.28 & 2.43 \\
\hline Brussels (13 km) & 1.20 & 1.23 & 1.25 & 1.47 & 1.68 & 2.09 & 1.99 & 1.76 & 1.84 & 2.13 & 2.43 & 2.60 \\
\hline Brussels $(18 \mathrm{~km})$ & 1.23 & 1.25 & 1.29 & 1.52 & 1.72 & 2.15 & 2.04 & 1.80 & 1.86 & 2.15 & 2.43 & 2.60 \\
\hline London $(5.5 \mathrm{~km})$ & 0.64 & 0.68 & 0.79 & 1.17 & 1.40 & 1.80 & 1.79 & 1.33 & 1.52 & 1.83 & 1.98 & 2.02 \\
\hline London $(8 \mathrm{~km})$ & 0.71 & 0.74 & 0.84 & 1.23 & 1.47 & 1.88 & 1.87 & 1.38 & 1.58 & 1.90 & 2.05 & 2.10 \\
\hline London $(13 \mathrm{~km})$ & 0.75 & 0.76 & 0.84 & 1.25 & 1.50 & 1.97 & 1.94 & 1.45 & 1.66 & 2.01 & 2.14 & 2.18 \\
\hline London $(18 \mathrm{~km})$ & 0.77 & 0.77 & 0.85 & 1.28 & 1.55 & 2.01 & 1.99 & 1.48 & 1.69 & 2.03 & 2.16 & 2.21 \\
\hline Paris $(5.5 \mathrm{~km})$ & 0.95 & 1.04 & 1.00 & 1.32 & 1.55 & 1.89 & 1.94 & 1.54 & 1.80 & 1.96 & 2.17 & 2.37 \\
\hline Paris $(8 \mathrm{~km})$ & 1.07 & 1.14 & 1.06 & 1.36 & 1.63 & 1.97 & 2.02 & 1.60 & 1.88 & 2.05 & 2.27 & 2.47 \\
\hline Paris $(13 \mathrm{~km})$ & 1.15 & 1.19 & 1.09 & 1.42 & 1.69 & 2.09 & 2.12 & 1.68 & 2.01 & 2.18 & 2.38 & 2.60 \\
\hline Paris $(18 \mathrm{~km})$ & 1.18 & 1.22 & 1.12 & 1.45 & 1.75 & 2.17 & 2.18 & 1.72 & 2.03 & 2.22 & 2.41 & 2.63 \\
\hline Munich $(5.5 \mathrm{~km})$ & 0.98 & 1.26 & 1.39 & 1.38 & 1.36 & 1.84 & 1.66 & 1.80 & 1.98 & 2.14 & 2.49 & 2.76 \\
\hline Munich $(8 \mathrm{~km})$ & 1.08 & 1.38 & 1.48 & 1.44 & 1.42 & 1.93 & 1.72 & 1.88 & 2.05 & 2.24 & 2.59 & 2.88 \\
\hline Munich $(13 \mathrm{~km})$ & 1.16 & 1.46 & 1.54 & 1.53 & 1.51 & 2.06 & 1.84 & 2.00 & 2.19 & 2.44 & 2.76 & 3.07 \\
\hline Munich $(18 \mathrm{~km})$ & 1.22 & 1.54 & 1.63 & 1.60 & 1.58 & 2.16 & 1.90 & 2.08 & 2.24 & 2.49 & 2.84 & 3.15 \\
\hline
\end{tabular}

terms of both computational time and relatively low error scores $\left(<2^{\circ} \mathrm{C}\right)$ and in terms of the application to energy consumption models.

In addition to the MAE, which gives an idea of the average magnitude of the forecast errors, the RMSE (root mean square error) puts in evidence the biggest temperature errors at the different lead times. This may be a useful performance analysis parameter, although it does not give information about deviations as the ME (mean error). Concerning the ME analysis (not presented here, for the sake of brevity), it exhibits a general underestimation over Italian cities, while an opposite behaviour is found over European ones. This outcome needs to be further investigated. Afterwards, the RMSE performance over Italian (Table 3) and European cities is shown (Table 4).

Results presented in the Tables 1-4 faithfully follow the MAE behaviour, particularly for Italian cities. It clearly appears, as above described, how large errors are enhanced from day +7 onwards at all grid resolutions and from day +5 for coarser ones (13 and $18 \mathrm{~km}$ ). Particularly, it is interesting to note the performance at $18 \mathrm{~km}$ grid resolution for Torino, where the presence of the surrounding Alps likely induces errors beyond the $2^{\circ} \mathrm{C}$ threshold from day +2 . For European cities, instead, a better performance is overall confirmed although some flaws are even found from day +5 for the lower grid resolutions. Again, the $8 \mathrm{~km}$ grid resolution represents the optimal choice for all the analysed cities in terms of performance and computational costs, considering the model runs several times a day.

4.3. Stable and Unstable Weather Condition Periods. The abovementioned study highlights general results over a period of two years. A subsequent deeper investigation is carried out using the $2 \mathrm{~m}$ temperature variable over particular periods characterized by opposite weather pattern configurations in order to evaluate if the e- $\mathrm{kmf}^{\mathrm{TM}}$ performance is enhanced or smoothed at different grid resolutions. 

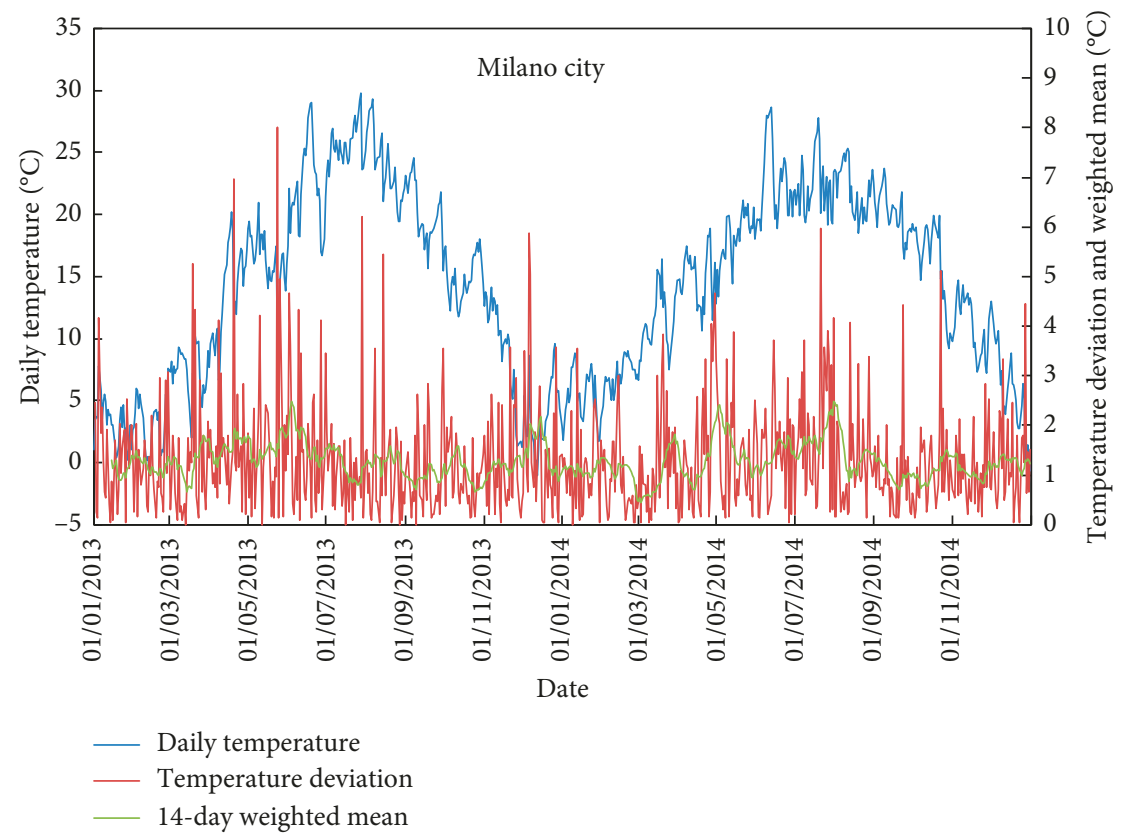

FiguRE 4: Observed daily temperatures (blue line) and deviations (red line) with the 14-day weighted mean (green line) over the analysed dataset: an example of the Milano city.

The following steps describe the adopted methodology chosen for selecting stable and unstable periods through temperature data only. First of all, we calculated the daily mean temperature $\left(T_{\text {daily mean }}\right)$ from observed hourly temperature data (original dataset), then the daily temperature differences between day +0 and day -1 ( $T$ deviations); then, we calculated the weighted mean of $T$ deviations on a moving window of 14 days ( $T$-weighted mean), and finally, the highest value of $T$-weighted mean has been associated to an unstable period, while the lowest value to a stable period for each city, as shown in Figure 4 for the example of Milano city.

Two stable periods in winter and summer and two unstable periods in spring and autumn were selected accordingly to a similar synoptic pattern found over the eight cities at the same time and in accordance with the calculations of the weighted temperature mean.

(i) $1^{\text {st }}$ unstable period: $14-27$ April 2013

(ii) $2^{\text {nd }}$ unstable period: 28 October-10 November 2013

(iii) $3^{\text {rd }}$ stable period: 23 January-5 February 2014

(iv) $4^{\text {th }}$ stable period: 23 June-7 July, 2015, where the presence of the massive high pressure in the summer 2015 over the greatest part of Europe let to choose a period (out of the original dataset) which was mutually stable over all the eight Italian and European cities.

For the sake of brevity, in the following pictures, we show the comparison for the $1^{\text {st }}$ (unstable) and the $4^{\text {th }}$ (stable) periods for the eight cities and for all lead times at different grid model resolutions.

It clearly appears how the spread between the MAE for Italian and European cities is confirmed here, and, even wider, worsening the grid resolution model (Figure 5). Forecast errors are between 2 and $4^{\circ} \mathrm{C}$ from the sixth day onwards during the unstable period and they can reach even $5^{\circ} \mathrm{C}$ as temperature deviation with a coarser resolution model.

On the contrary, during the presence of the July 2015 anticyclone which embraced the whole of Europe, the performances of the e-kmf ${ }^{\mathrm{TM}}$ are higher, as logically one can expect. The MAE remains below the $2^{\circ} \mathrm{C}$ error threshold event at lower model resolution (Figure 6), expect for Torino and Milano where local topography plays a crucial role, and the temperature forecast errors reach $4^{\circ} \mathrm{C}$ and $5^{\circ} \mathrm{C}$ as differences with local observations with the $13 \mathrm{~km}$ and $18 \mathrm{~km}$ grid resolution.

Considering these selected periods, the presence of synoptic-scale high pressure generally increases the forecast horizon reducing the impact of grid resolution. On the other side, in unstable weather conditions, generally responsible of abrupt changes in observed temperatures, the MAE increases as grid resolution decreases, especially for places where influences of the terrain may become relevant.

\section{Conclusions}

The analysis about temperature forecast errors has been carried out over eight cities among Italian and European cities during the years 2013 and 2014 and, afterwards, for four periods of two weeks with different synoptic conditions. The MAE and RMSE are used to calculate the performance analysis between observed data and meteorological output of the $\mathrm{e}-\mathrm{kmf}^{\mathrm{TM}}$ weather forecast model at different spatial resolutions $(5.5,8,13$, and $18 \mathrm{~km})$.

The aim of the study is to analyse the role of spatial resolution on temperature forecasts of the $\mathrm{e}-\mathrm{kmf}^{\mathrm{TM}}$ model for 


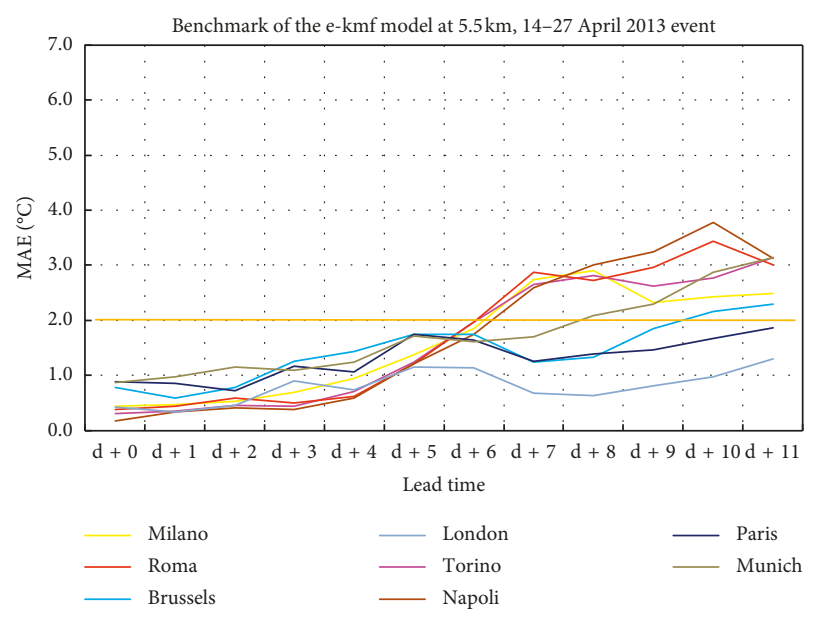

(a)

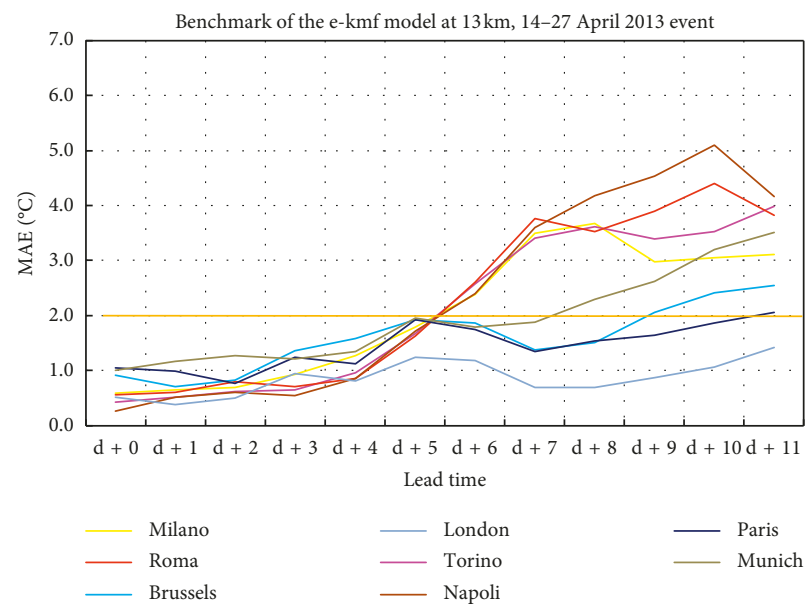

(c)

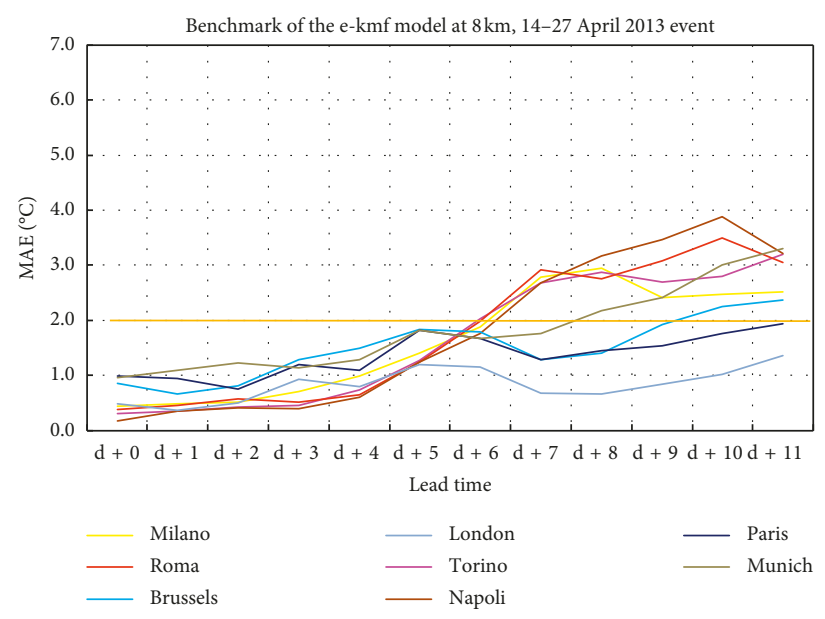

(b)

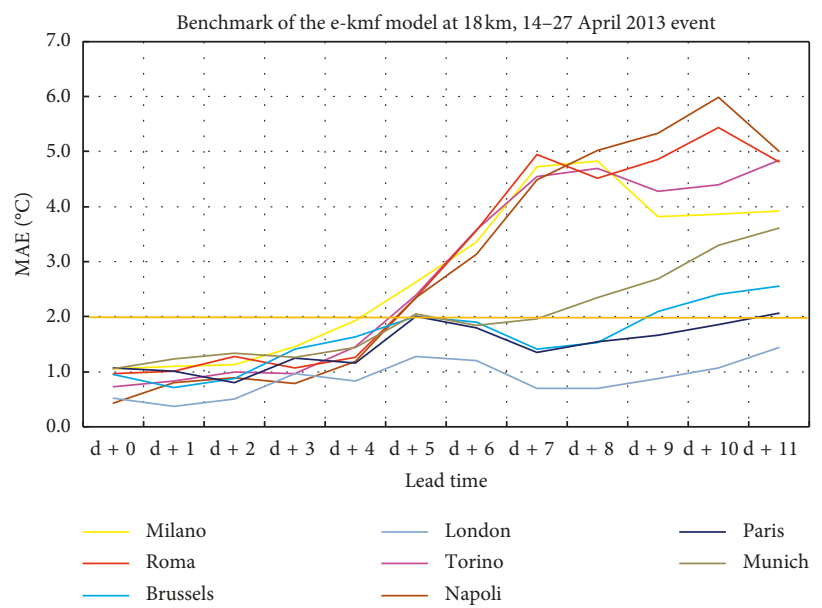

(d)

Figure 5: Comparison of the MAE for the 14-27 April 2013 episode between the e-kmf ${ }^{\mathrm{TM}}$ model at different grid resolutions over all the analysed cities from day +0 to day +11 as lead time of forecast.

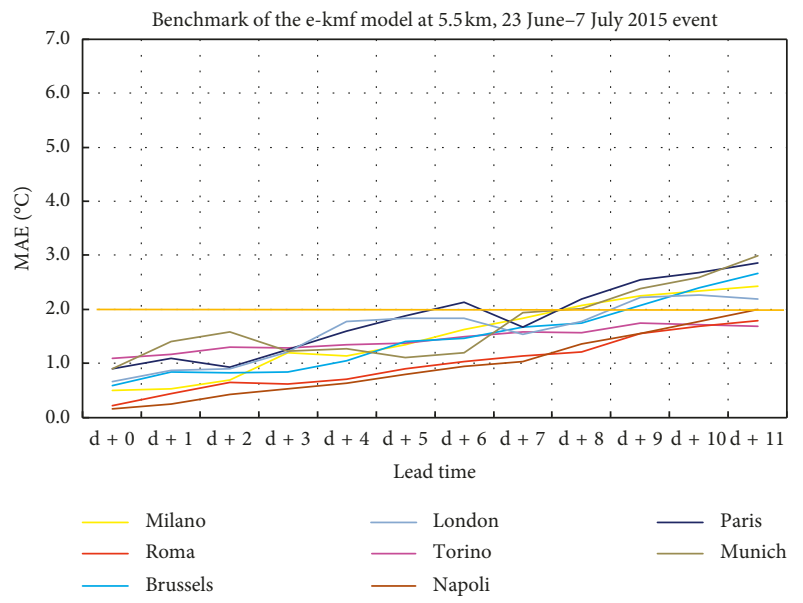

(a)

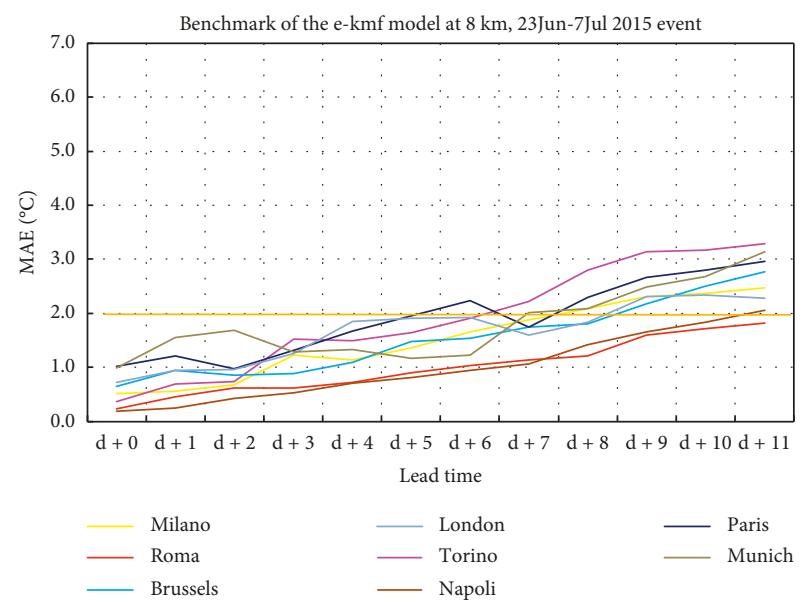

(b)

Figure 6: Continued. 


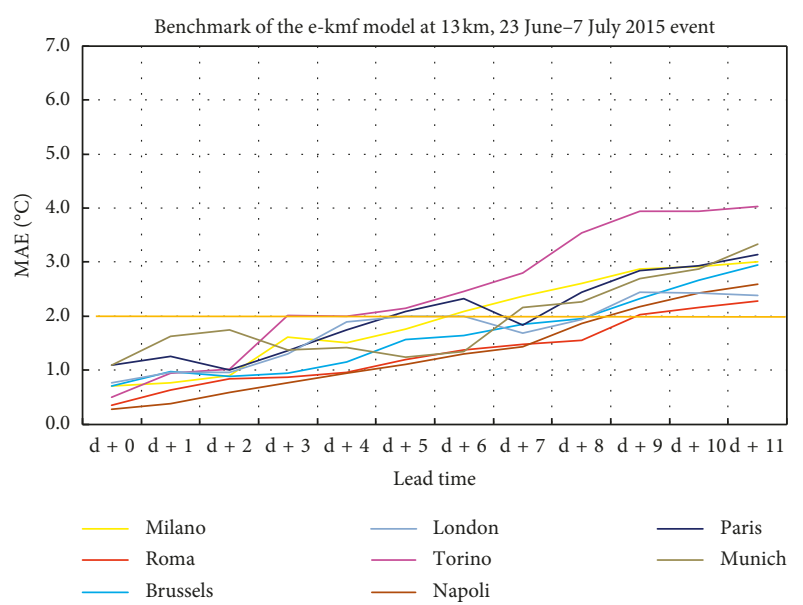

(c)

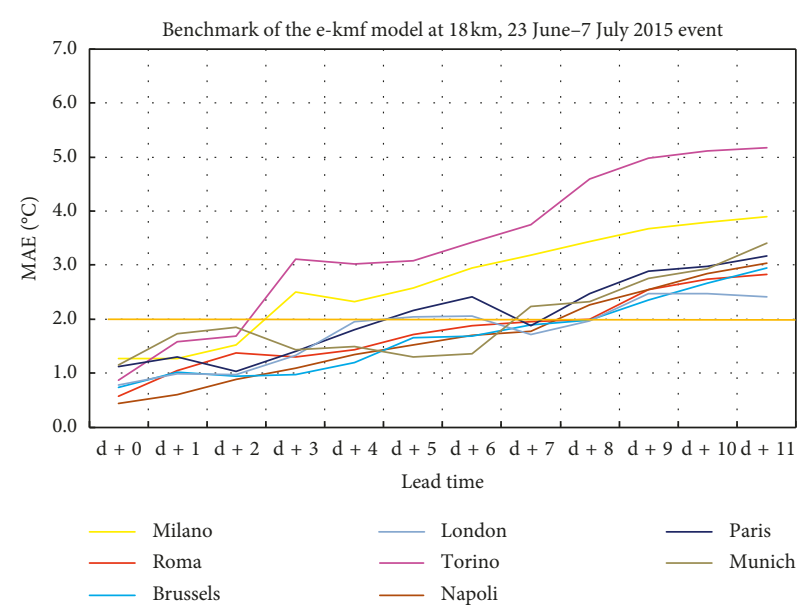

(d)

FIgure 6: Comparison of the MAE for the 23 June-7 July 2015 episode between the e-kmf ${ }^{\mathrm{TM}}$ model at different grid resolutions over all the analysed cities from day +0 to day +11 as lead time of forecast.

those sites characterized by different climate and terrain conditions as tested by the four European cities (London, Paris, Brussels, and Munich) and the four Italian cities (Milano, Torino, Roma, and Napoli). Results on the e-kmf ${ }^{\mathrm{TM}}$ spatial resolution analysis show the role of grid size on model performances at any lead time (up to day +11 ). In particular, the spatial resolution change from 18 to $5.5 \mathrm{~km}$ is more relevant over the Italian (Mediterranean) cities than the European (continental) ones, since these are affected by Atlantic climate conditions. A temperature score lower than $2^{\circ} \mathrm{C}$ (MAE and RMSE), which can be considered an acceptable threshold for an effective temperature forecast in energy consumption applications, is achieved using the forecast model with $5.5 \mathrm{~km}$ grid resolution up to day +5 in Milano and Torino, up to day +6 in Napoli and Roma, and up to day +9 in Brussels, Paris, and London. RMSE analysis for Torino (close to the Alpine region) exhibits the lowest performance score at the coarsest resolution model $(18 \mathrm{~km})$ already since the day +2 forecast, showing the importance of the surrounding terrain characteristics. For an operative application over both Italian and European cities by minimizing the computational costs, a proper grid size might be $8 \mathrm{~km}$. Finally, considering that it is used as a single daily value in the energy consumption operational prediction model, this benchmark analysis has only looked at the ensemble mean value of temperatures. A future development will account for each forecast ensemble member individually in order to generate a probability distribution for energy consumption predictions.

\section{Abbreviations}

e-kmf ${ }^{\mathrm{TM}}$ : eni-kassandra meteo forecast

IDW: Inverse distance weighting

MAE: Mean absolute error

METAR: Meteorological aerodrome report

NWP model: Numerical weather prediction model

SYNOP: $\quad$ Surface Synoptic observations.

\section{Data Availability}

The data used to support the findings of this study are available from the corresponding author upon request.

\section{Conflicts of Interest}

The authors declare that they have no conflicts of interest (neither financial nor nonfinancial ones).

\section{Authors' Contributions}

AC was involved in the benchmark analysis and data interpretation and wrote most of this manuscript. GG was involved in research project development, industrial applications, and revision. RS developed the weather forecast model, collected all observed datasets, and supervised all data simulations. GE was involved in data model analysis and debugging. MM supervised the complete manuscript and approved the final version to be published.

\section{Acknowledgments}

This research was carried out in the framework of the Kassandra Meteo Project funded by Eni S.p.A.

\section{References}

[1] R. T. Sutton and D. L. R. Hodson, "Atlantic ocean forcing of north American and European summer climate," Science, vol. 309, no. 5731, pp. 115-118, 2005.

[2] J. Sheffield, G. Goteti, and E. F. Wood, "Development of a 50year high-resolution global dataset of meteorological forcings for land surface modeling," Journal of Climate, vol. 19, no. 13, pp. 3088-3111, 2006.

[3] G. Giunta and R. Salerno, "Short-long term temperature forecasting method and system for production management and sale of energy resources," Patent EP 2859389B1, 2017. 
[4] P. Potocnik, M. Thaler, E. Govekar, I. Grabec, and A. Poredos, "Forecasting risks of natural gas consumption in Slovenia," Energy Policy, vol. 35, no. 8, pp. 4271-4282, 2007.

[5] M. De Felice, A. Alessandri, and F. Catalano, "Seasonal climate forecasts for medium-term electricity demand forecasting," Applied Energy, vol. 137, pp. 435-444, 2015.

[6] G. Giunta, R. Vernazza, R. Salerno, A. Ceppi, G. Ercolani, and M. Mancini, "Hourly weather forecasts for gas turbine power generation," Meteorologische Zeitschrift, vol. 26, no. 3, pp. 307-317, 2017.

[7] G. Giunta, R. Salerno, A. Ceppi, G. Ercolani, and M. Mancini, "Benchmark analysis of forecasted seasonal temperature over different climatic areas," Geoscience Letters, vol. 2, no. 1, p. 9, 2015.

[8] F. Mesinger, S. C. Chou, J. L. Gomes et al., "An upgraded version of the Eta model," Meteorology and Atmospheric Physics, vol. 116, no. 3-4, pp. 63-79, 2012.

[9] K.-S. S. Lim and S.-Y. Hong, "Development of an effective double-moment cloud microphysics scheme with prognostic cloud condensation nuclei (CCN) for weather and climate models," Monthly Weather Review, vol. 138, no. 5, pp. 1587-1612, 2010.

[10] S.-Y. Hong, J. Dudhia and S.-H. Chen, A revised approach to ice microphysical processes for the bulk parameterization of clouds and precipitation," Monthly Weather Review, vol. 132, no. 1, pp. 103-120, 2004.

[11] S.-Y. Hong, Y. Noh, and J. Dudhia, "A new vertical diffusion package with an explicit treatment of entrainment processes," Monthly Weather Review, vol. 134, no. 9, pp. 2318-2341, 2006.

[12] S.-Y. Hong, J. Choi, E.-C. Chang, H. Park, and Y.-J. Kim, "Lower-tropospheric enhancement of gravity wave drag in a global spectral atmospheric forecast model," Weather and Forecasting, vol. 23, no. 3, pp. 523-531, 2008.

[13] C. S. Bretherton and S. Park, "A new moist turbulence parameterization in the community atmosphere model," Journal of Climate, vol. 22, no. 12, pp. 3422-3448, 2009.

[14] J. E. Pleim, "A simple, efficient solution of flux-profile relationships in the atmospheric surface layer," Journal of Applied Meteorology and Climatology, vol. 45, no. 2, pp. 341-347, 2006.

[15] J. E. Pleim, "A combined local and nonlocal closure model for the atmospheric boundary layer. Part I: model description and testing," Journal of Applied Meteorology and Climatology, vol. 46, no. 9, pp. 1383-1395, 2007.

[16] A. C. Beljaars, "The parametrization of surface fluxes in largescale models under free convection," Quarterly Journal of the Royal Meteorological Society, vol. 121, no. 522, pp. 255-270, 1995.

[17] J. S. Kain, "The kain-fritsch convective parameterization: an update," Journal of Applied Meteorology, vol. 43, no. 1, pp. 170-181, 2004.

[18] J. Han and H.-L. Pan, "Revision of convection and vertical diffusion schemes in the NCEP global forecast system," Weather and Forecasting, vol. 26, no. 4, pp. 520-533, 2011.

[19] M. J. Iacono, J. S. Delamere, E. J. Mlawer, M. W. Shephard, S. A. Clough, and W. D. Collins, "Radiative forcing by longlived greenhouse gases: calculations with the AER radiative transfer models," Journal of Geophysical Research, vol. 113, no. D13, 2008.

[20] J. Dudhia, "Numerical study of convection observed during the winter monsoon experiment using a mesoscale twodimensional model," Journal of the Atmospheric Sciences, vol. 46, no. 20, pp. 3077-3107, 1989.
[21] E. J. Mlawer, S. J. Taubman, P. D. Brown, M. J. Iacono, and S. A. Clough, "Radiative transfer for inhomogeneous atmospheres: RRTM, a validated correlated-k model for the longwave," Journal of Geophysical Research: Atmospheres, vol. 102, no. D14, pp. 16663-16682, 1997.

[22] G.-Y. Niu, Z.-L. Yang, K. E. Mitchell et al., "The community Noah land surface model with multiparameterization options (Noah-MP): 1. Model description and evaluation with localscale measurements," Journal of Geophysical Research, vol. 116, no. D12, 2011.

[23] Z.-L. Yang, G.-Y. Niu, K. E. Mitchell et al., "The community Noah land surface model with multiparameterization options (Noah-MP): 2. Evaluation over global river basins," Journal of Geophysical Research, vol. 116, no. D12, 2011.

[24] J. Noilan and S. Planton, "A simple parameterization of land surface processes for meteorological models," Monthly Weather Review, vol. 117, no. 3, pp. 536-549, 1989.

[25] J. E. Pleim and A. Xiu, "Development and testing of a surface flux and planetary boundary layer model for application in mesoscale models," Journal of Applied Meteorology, vol. 34, no. 1, pp. 16-32, 1995.

[26] R. Salerno, "Model intercomparison for research and operational use: a case study in the alpine region," Croatian Meteorological Journal, vol. 40, pp. 423-426, 2005.

[27] R. Salerno, "Influence of model resolutions in high-mountain region: a verification against observations in selected case studies," in Proceedings of the 12th International Conference on Mountain Meteorology, American Meteorological Society, Santa Fe, NM, USA, August 2006.

[28] S. L. Mullen and R. Buizza, "The impact of horizontal resolution and ensemble size on probabilistic forecasts of precipitation by the ECMWF ensemble prediction system," Weather and Forecasting, vol. 17, no. 2, pp. 173-191, 2002.

[29] X. Wang, P. Steinle, A. Seed, and Y. Xiao, "The sensitivity of heavy precipitation to horizontal resolution, domain size, and rain rate assimilation: case studies with a convectionpermitting model," Advances in Meteorology, vol. 2016, Article ID 7943845, 20 pages, 2016.

[30] J. Hoadley, M. Rorig, K. Westrick et al., "Assessing the value of increased model resolution in forecasting fire danger," in Proceedings of the Second International Wildland Fire Ecology and Fire Management Congress and Fifth Symposium On Fire and Forest Meteorology, pp. 1-5, Orlando, FL, USA, November 2003.

[31] N. P. Wedi, "Increasing horizontal resolution in numerical weather prediction and climate simulations: illusion or panacea?," Philosophical Transactions of the Royal Society A: Mathematical, Physical and Engineering Sciences, vol. 372, no. 2018, article 20130289, 2014.

[32] A. M. Gadian, A. M. Blyth, C. L. Bruyere et al., "A case study of possible future summer convective precipitation over the UK and Europe from a regional climate projection," International Journal of Climatology, vol. 38, no. 5, pp. 2314-2324, 2018.

[33] Y. Wang, L. R. Leung, J. L. McGregor et al., "Regional climate modeling: progress, challenges, and prospects," Journal of the Meteorological Society of Japan. Ser. II, vol. 82, no. 6, pp. 1599-1628, 2004.

[34] C. F. Mass, D. Ovens, K. Westrick, and B. A. Colle, "Does increasing horizontal resolution produce more skillful forecasts?," Bulletin of the American Meteorological Society, vol. 83, no. 3, pp. 407-430, 2002.

[35] G. Zängl, "To what extent does increased model resolution improve simulated precipitation fields? A case study of two 
north-Alpine heavy-rainfall events," Meteorologische Zeitschrift, vol. 16, no. 5, pp. 571-580, 2007.

[36] H. Zhang, Z. Pu, and X. Zhamg, "Examination of errors in near-surface temperature and wind from WRF numerical simulations in regions of complex terrain," Weather and Forecasting, vol. 28, no. 3, pp. 893-914, 2013.

[37] K. A. Hart, W. J. Steenburgh, and D. J. Onton, "Model forecast improvements with decreased horizontal grid spacing over finescale intermountain orography during the 2002 olympic winter games," Weather and Forecasting, vol. 20, no. 4, pp. 558-576, 2005.

[38] J. W. Taylor and R. Buizza, "A comparison of temperature density forecasts from GARCH and atmospheric models," Journal of Forecasting, vol. 23, no. 5, pp. 337-355, 2004.

[39] I. Sandu, A. Zadra, and N. Wedi, On the Impact of Orographic Drag on Forecast Skill, 2016, European Centre for MediumRange Weather Forecast, Reading, UK, 2016. 

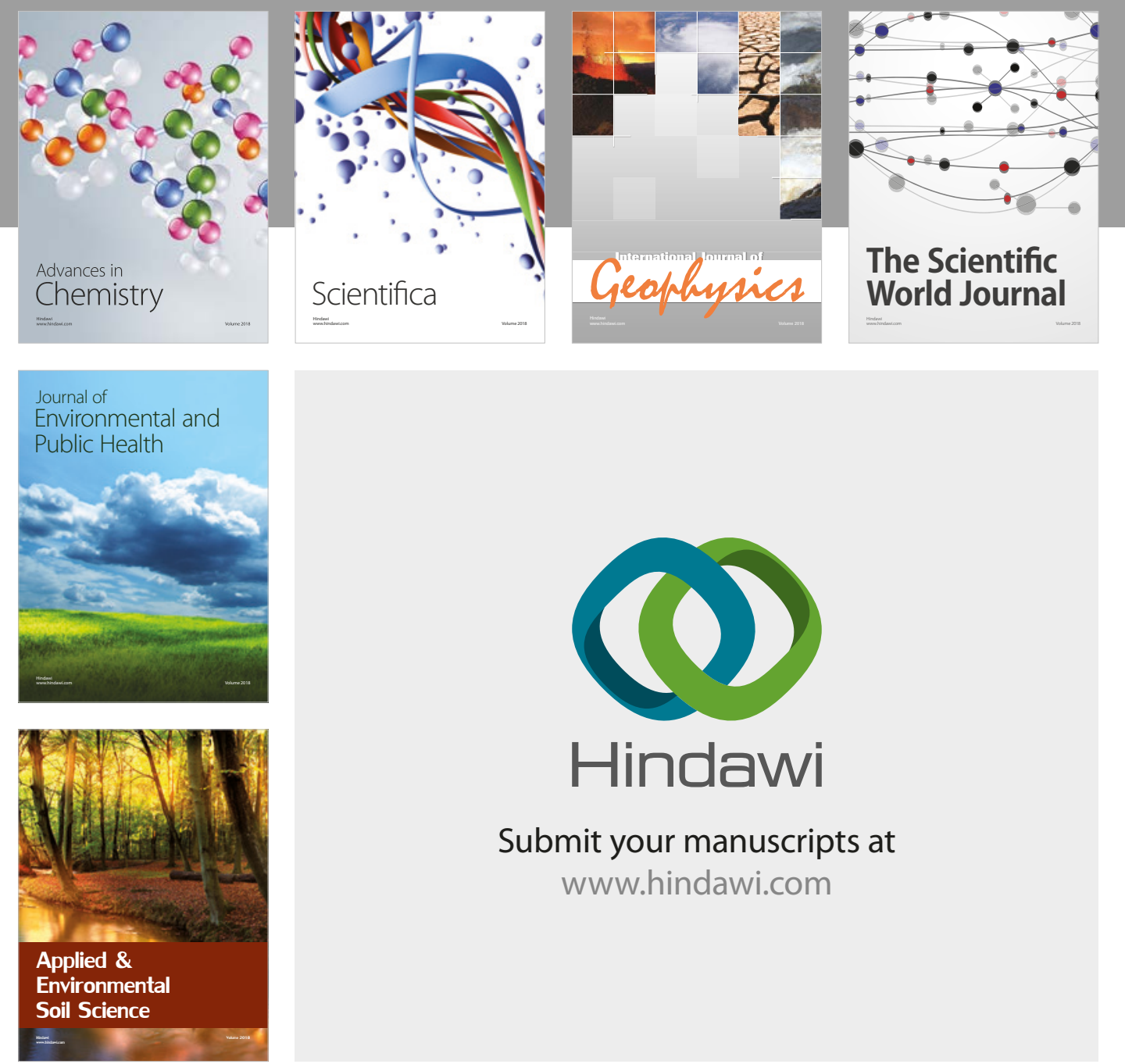

The Scientific

\section{World Journal}
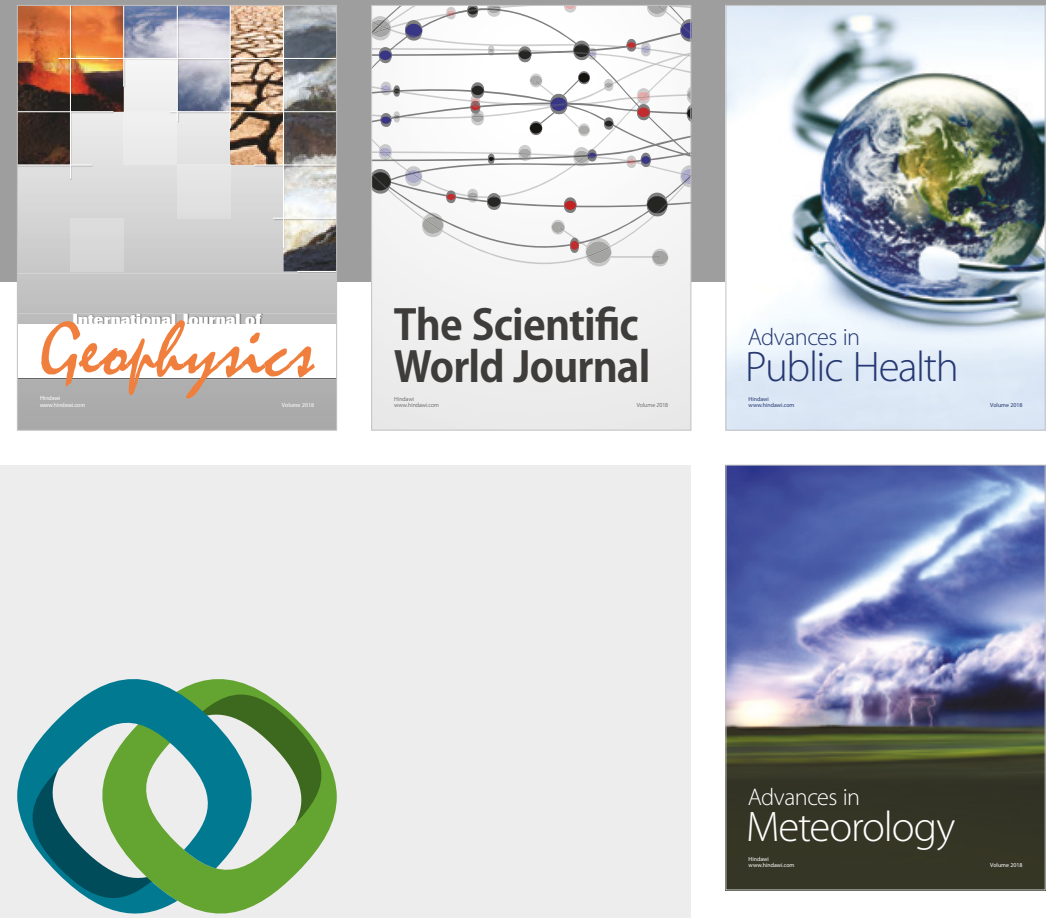

Advan

Public Health

\section{Hindawi}

Submit your manuscripts at

www.hindawi.com
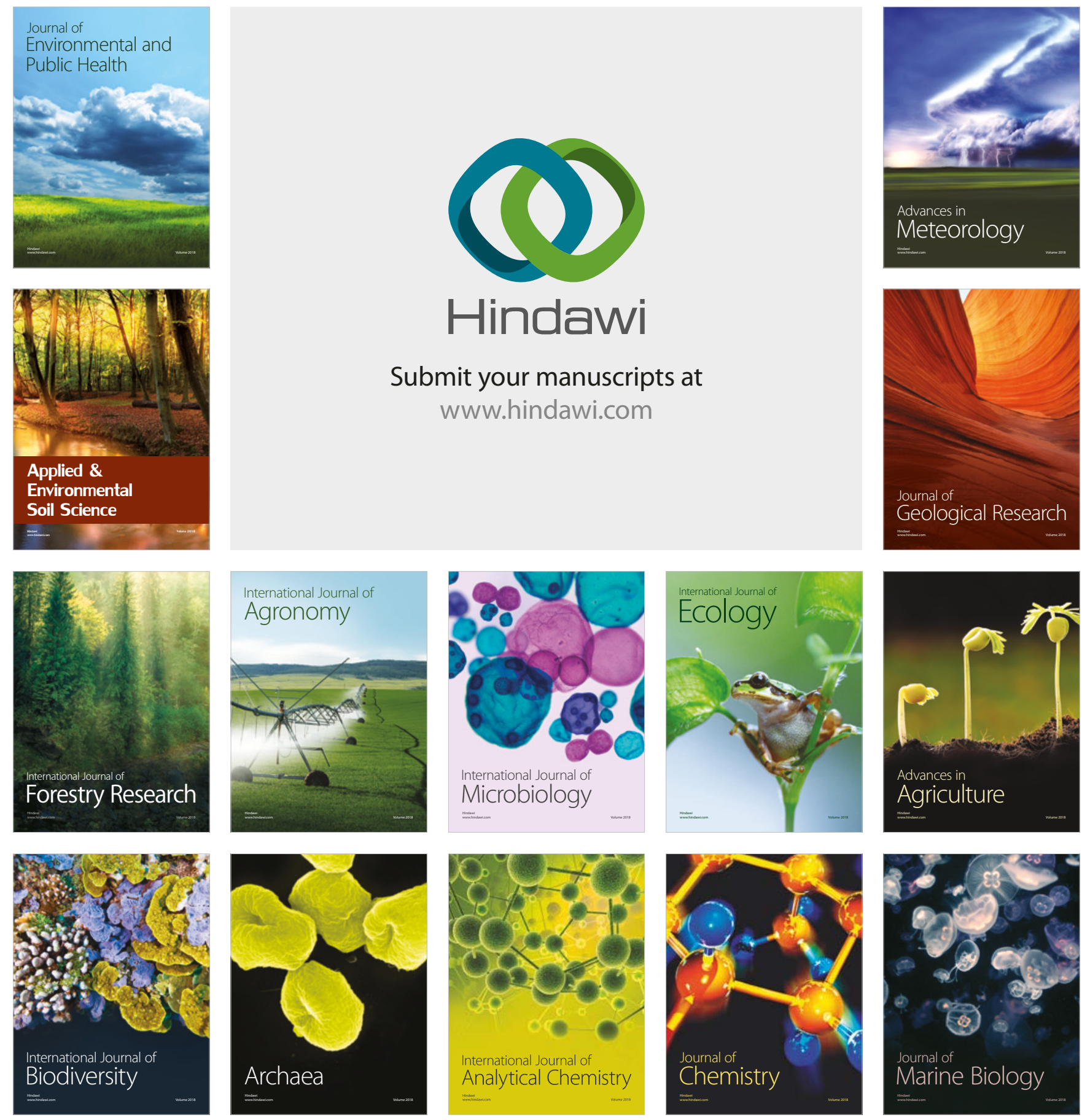